\title{
Profil Penderita Stroke Berulang Rumah Sakit Muhammadiyah Malang Periode Juli-Agustus 2019
}

\author{
Risma Karlina Prabawati ${ }^{1}$, Azizah Siena Pitaloka ${ }^{1}$ \\ ${ }^{1}$ Fakultas Kedokteran Universitas Muhammadiyah Malang \\ Jalan Bendungan Sutami no. 188 A Malang
}

rismakarlina@gmail.com

\begin{abstract}
Stroke can affect the patient's life, either in the form of disability or death. Stroke is divided into ischemic and hemorrhagic stroke. The occurrence of recurrent stroke can affect the cognitive status and life expectancy of patients. This study aims to determine the profile of recurrent stroke patients at the Neurology Polyclinic of Muhammadiyah Hospital Malang in July-August 2019. This study is a descriptive study with a cross sectional approach. Recurrent stroke occurred mostly in men $(54.26 \%)$, aged 56-65 years $(41.5 \%)$, and the level of college education (30\%). Recurrent stroke often occurs in patients with a higher age, higher education, and a history of hypertension. Promotive and preventive efforts in the form of education and health promotion should always be carried out to prevent recurrent strokes that are at risk of worsening cognitive function.
\end{abstract}

Key Words: Recurrent Stroke, Profile, Muhammadiyah Malang

\section{Abstrak}

Stroke dapat mempengaruhi kehidupan penderita, baik berupa kecacatan maupun kematian. Stroke dibagi menjadi stroke iskemik dan perdarahan. Terjadinya stroke berulang dapat mempengaruhi status kognitif dan angka harapan hidup penderita. Penelitian ini bertujuan untuk mengetahu profil penderita stroke berulang di Poliklinik Saraf Rumah Sakit Muhammadiyah Malang pada bulan Juli-Agustus 2019. Penelitian ini merupakan penelitian deskriptif dengan pendekatan cross sectional. Stroke berulang terjadi terbanyak pada laki-laki (54.26\%), usia 56-65 tahun (41.5\%), dan tingkat pendidikan perguruan tinggi (30\%). Stroke berulang sering terjadi pada pasien dengan usia yang lebih tinggi, pendidikan tinggi, dan adanya riwayat Hipertensi. Upaya promotive dan preventif berupa edukasi dan promosi kesehatan sebaiknya selalu dilakukan agar tidak terjadi stroke berulang yang beresiko memperburuk fungsi kognitif.

Kata Kunci: Stroke berulang, Profil, Muhammadiyah Malang 


\section{Pendahuluan}

Tingginya jumlah pasien stroke di Indonesia dari hasil diagnosis tenaga kesehatan diperkirakan sejumlah 1.236.825 orang $(7,0 \%)$, sedangkan dari gejala yang ada diperkirakan sebanyak 2.137 .941 orang $(12,1 \%)$. Provinsi Jawa Timur memiliki estimasi jumlah pasien stroke terbanyak kedua di Indonesia, yaitu 190.449 orang $(6,6 \%)$ dan 302.987 orang $(10,5 \%)^{1}$. Berdasarkan data Rumah Sakit Universitas Muhammadiyah Malang (RS UMM), jumlah pasien stroke masih sangat banyak dan memiliki angka kejadian yang tinggi. Hal tersebut dapat dilihat dari daftar penyakit 10 terbanyak di RS UMM tahun 2015, angka kesakitan yang disebabkan oleh penyakit kronis terbanyak adalah stroke dengan jumlah 33 pasien dalam bulan Mei - September 2015². Stroke ditandai dengan defisit neurologi serebral yang berkembang cepat dan dapat menyebabkan kematian disebabkan kejadian vaskular berupa perdarahan spontan pada otak maupun suplai darah yang inadekuat pada bagian otak ${ }^{3}$. Seseorang yang sembuh dari serangan stroke pertama mempunyai resiko untuk mengalami serangan stroke yang kedua atau berulang di kemudian hari ${ }^{4}$. Kejadian stroke berulang akan mempengaruhi status kognitif pasien stroke dan merupakan kasus fatalitas yang tinggi ${ }^{5}$.

Penelitian ini bertujuan untuk mengetahui profil penderita stroke berulang di RS UMM periode JuliAgustus 2019. Penelitian ini penting dilakukan untuk mengetahui faktor-faktor yang dapat mempengaruhi terjadinya stroke berulang. Apabila faktor tersebut dapat dikendalikan maka akan membantu prevensi terhadap stroke berulang.

\section{METODE}

Penelitian ini merupakan penelitian deskriptif dengan pendekatan cross-sectional. Penelitian ini akan dilakukan di Poliklinik Saraf Rumah Sakit Universitas Muhammadiyah Malang yang direncanakan berlangsung pada bulan Juli-Agustus 2019. Populasi pasien ini adalah seluruh pasien stroke Poliklinik Saraf RS UMM pada bulan Juli-Agustus 2019. Sementara, sampel penelitiannya adalah pasien stroke berulang Poliklinik Saraf RS UMM dengan periode yang sama. Besar sampe minimal 94 orang dengan Teknik nonprobability sampling dengan metode consecutive sampling. Pasien stroke berulang dengan demensia non vaskuler dan adanya riwayat trauma kepala, retardasi mental, gangguan psikiatri dan psikososial berat dikeluarkan dari sampel penelitian.

Stroke berulang merupakan stroke serangan kedua atau lebih pada pasien stroke RS UMM. Alat ukurnya berupa Rekam Medis dan skala ordinal. Pada rekam medis juga akan didapatkan data jenis kelamin, usia, Pendidikan dan riwayat penyakit dahulu. Pada saat kunjungan Poliklinik maka akan diambil data status kognitif berupa pemeriksaan MMSE (Mini Mental State Examination). Total skor MMSE 0-30.

Peneliti akan memilih sampel sesuai dengan kriteria inklusi dan eksklusi, kemudian dilakukan 
informed consent kepada responden mengenai penelitian yang akan dilakukan dan meminta pernyataan kesediaannya menjadi sampel dalam penelitian. Kemudian dilakukan wawancara dan pengukuran MMSE. Data wawancara dan MMSE diambil oleh selain peneliti untuk menjaga validitas penelitian. Data kemudian dianalisa dengan metode yang sesuai. Analisis univariat untuk mengetahui distribusi frekuensi karakteristik subyek dan proporsi setiap variabel menggunakan SPSS 24.

Tabel 1. Karakteristik Pasien Stroke Berulang RS UMM Juli-Agustsu 2019

\begin{tabular}{|c|c|c|c|}
\hline Karakteristik & & $\mathbf{n}$ & $\%$ \\
\hline \multirow[t]{2}{*}{ Jenis Kelamin } & Laki-Laki & 51 & 54.26 \\
\hline & Perempuan & 43 & 45.74 \\
\hline \multirow[t]{5}{*}{ Usia } & $26-35$ & 3 & 3.19 \\
\hline & $36-45$ & 2 & 2.13 \\
\hline & $46-55$ & 20 & 21.28 \\
\hline & $56-65$ & 39 & 41.50 \\
\hline & 66-ke atas & 30 & 31.91 \\
\hline \multirow[t]{5}{*}{ Pendidikan } & Tidak sekolah & 8 & 8.51 \\
\hline & SD & 21 & 22.34 \\
\hline & SMP & 16 & 17.02 \\
\hline & SMA & 19 & 20.21 \\
\hline & Perguruan Tinggi & 30 & 31.91 \\
\hline Penyakit & Tidak ada & 40 & 42.55 \\
\hline \multirow[t]{3}{*}{ Dahulu } & Hipertensi & 41 & 43.62 \\
\hline & Jantung/PJK & 7 & 7.45 \\
\hline & Diabetes Mellitus & 6 & 6.38 \\
\hline
\end{tabular}

\section{HASIL DAN PEMBAHASAN}

Penelitian telah dilakukan di Poli Syaraf RS UMM dari 1 Juli -30 Agustus 2019. Dari penelitian tersebut didapatkan 94 orang sampel. Kemudian dilakukan wawancara dengan seluruh responden dan pemeriksaan MMSE. Hasil karakteristik pasien stroke berulang tersebut ditampilkan pada Tabel 1. 


\begin{tabular}{|c|c|c|c|}
\hline Frekuensi Serangan & $1 x$ & 49 & 52.13 \\
\hline Stroke Berulang & $>1 x$ & 45 & 47.87 \\
\hline \multirow[t]{4}{*}{ Status Kognitif } & Normal & 51 & 54.26 \\
\hline & Gangguan & 28 & 29.79 \\
\hline & Ringan & & \\
\hline & Gangguan Kognitif Berat & 15 & 15.96 \\
\hline Total & & 94 & 100 \\
\hline
\end{tabular}

Dari seluruh pasien stroke berulang, proporsi terbanyak adalah pada laki-laki. Hal tersebut sesuai dengan penelitian lain di Yogyakarta. Pada 1053 kasus stroke di 5 rumah sakit di Yogyakarta angka kematian tercatat sebesar 28.3\%; sedangkan pada 780 kasus stroke iskemik adalah 20,4\%, lebih banyak pada laki-laki ${ }^{15}$. Distribusi kelompok usia terbanyak adalah pada usia 56-65 tahun. Hal tersebut sesuai dengan penelitian di RSUD Moewardi, bahwa dari 58 sampel yang ada didapatkan pasien stroke terbanyak pada kelompok usia antara 56-65 $\operatorname{tahun}^{15}$. Peningkatan umur berhubungan dengam proses penuaan, seluruh organ tubuh mengalami kemunduran fungsi termasuk pembuluh darah otak. Pembuluh darah menjadi tidak elastis terutama bagian endotel yang mengalami penebalan pada tunika intima. Hal ini akan mengakibatkan lumen menjadi sempit dan penurunan aliran darah ke otak.

Penelitian ini juga mengelompokkan berdasarkan pendidikan pasien stroke berulang. Pada data ditemukan paling tinggi adalah tingkat Perguruan
Tinggi. Hal ini kemungkinan disebabkan gaya hidup sedentary yang rata-rata dimiliki oleh orang yang berpendidikan tinggi. Stress dan aktivitas fisik juga dapat mempengaruhi terjadinya gangguan vascular ${ }^{16}$. Hipertensi menempati riwayat penyakit dahulu terbanyak pada penelitian ini. Hipertensi diketahui akan menyebabkan resiko pecah dan tersumbatnya pembuluh darah, serta akan menyebabkan stroke berulang dan memperburuk fungsi kognitif ${ }^{11}$. Status kognitif ditemukan paling banyak adalah normal (54.26\%). Hal ini kemungkinan diakibatkan karena lesi yang terjadi di otak adalah kecil/lacunar sehingga tidak mempengaruhi langsung fungsi kognitif. Penurunan status kognitif dapat disebabkan oleh berbagai faktor. Salah satunya adalah frekuensi berulangnya stroke seperti penelitian yang akan dilakukan. akan tetapi, terdapat pula berbagai faktor yang dapat menyebabkan status kognitif menurun selain stroke yang berulang. Faktor-faktor tersebut yakni terdiagnosis demensia, mengalami cedera kepala, mengalami retardasi mental, mengalami gangguan psikiatri, serta mengalami 
masalah psikososial berat ${ }^{17}$. Frekuensi gangguan

kognitif pada pasien post-stroke sebanyak 20-30\%, dan semakin meningkat resikonya untuk mengalami penurunan fungsi kognitif, bahkan hingga 2 tahun poststroke. Pasien post-stroke termasuk di dalam kelompok gangguan kognitif yakni Vascular Cognitive Impairment (VCI), meliputi gangguan kognitif ringan dan tidak mengganggu aktivitas sehari-hari (Vascular Cognitive NoDementia) hingga gangguan yang paling berat berupa demensia vaskuler. Selain itu, gangguan kognitif dapat mengenai satu atau lebih bagian kognitif seperti atensi, bahasa, memori, visuospasial, serta fungsi eksekutif ${ }^{18}$.

\section{KESIMPULAN DAN SARAN}

Stroke berulang sering terjadi pada pasien dengan usia yang lebih tinggi, pendidikan tinggi, dan adanya riwayat Hipertensi. Faktor resiko tersebut dapat berbeda-beda pada setiap Rumah Sakit, tetapi kemungkinannya tidak berbeda jauh. Upaya promotive dan preventif berupa edukasi dan promosi kesehatan sebaiknya selalu dilakukan agar tidak terjadi stroke berulang yang beresiko memperburuk fungsi kognitif.

\section{DAFTAR PUSTAKA}

1. Kementerian Kesehatane Republik Indonesia, 2013, Riset Kesehatan Dasar 2013. Jakarta: Badan Penelitian dan Pengembangan Kesehatan KEMENKES RI.

2. Prasetyo YB, Djauhari T, Wardojo SSI, 2016, Potensi Layanan Homecare di RS UMM didasarkan pada Analisa Kasus Penyakit, Ekonomi dan Sosial Masyarakat, Jurnal Keperawatan, 7(1), pp. 70-78.

3. Setiati S, Alwi I, Sudayana AW, Simadibrata M, Setiyohadi B, Syam AF, 2014, Buku Ajar
Ilmu Penyakit Dalam Jilid II Edisi VI, Jakarta: Interna Publishing.

4. Go AS, Mozaffarian D, Roger VL, Benjamin EJ, Berry JD, Blaha MJ, Dai S, Ford ES, Fox CS, Franco S, Fullerton HJ, Gillespie C, Hailpern SM, Heit JA, Howard VJ, Huffman MD, Judd SE, Kissela BM, Kittner SJ, Lackland DT, Lichtman JH, Lisabeth LD, Mackey RH, Magid DJ, Marcus GM, Marelli A, Matchar DB, McGuire DK, Mohler III ER, Moy CS, Mussolino ME, Neumar RW, Nichol G, Pandey DK, Paynter NP, Reeves MJ, Sorlie PD, Stein J, Towfighi A, Turan TN, Virani SS, Wong ND, Woo N, Turner MB, 2014, Heart Disease and Stroke Statistics2014 Update A Report From the American Heart Association, Circulation, 129, pp. e28e292.

5. Ispas D, Borman WC, 2015, Psychology of Personnel Selection, International Encyclopedia of the Social \& Behavioral Sciences (Second Edition), 17, pp. 936-940

6. PERDOSSI. Acuan Panduan Praktik Klinis Neurologi. Perhimpunan dokter Spesialis Saraf Indonesia, 2016, $150-156 \mathrm{p}$

7. AHA/ASA Guideline for the Perevention of Stroke in Patien with Stroke or Transient Ischemic Attack. Stroke, 2014, Vol 42;227$276 \mathrm{p}$

8. Jones, Sen S, Lakshminarayan K, Rosamond WD, 2013, Post stroke Outcomes Vary by Pathogenic Stroke Subtype in The Atherosclerosis Risk in Communities Study, Stroke - Journal of The American Heart Association, 44, pp. 2307-2310.

9. Zhu R, Xu K, Shi J, Yan Q, 2016, Time Interval Between First Ever and Recurrent Stroke in A Population Hospitalized for Second Stroke: A Retrospective Study, Neurology Asia, 21(3), pp. 209 - 216.

10. Rahayu S, Utomo W, Utami S, 2014, Hubungan Frekuensi Stroke dengan Fungsi Kognitif di RSUD Arifin Achmad, JOM PSIK, 1(2), pp. 1-10.

11. Ying CY, Harith S, Ahmad A, Mukhali HB, 2018, Prevalence, Risk Factors and Secondary Prevention of Stroke Recurrence in Eight Countries From South, East Southeast Asia A Scoping Review, Med J Malaysia, 73(2), pp. 90-99.

12. Sun J, Tan L, Yu J, 2014, Post-Stroke Cognitive Impairment: Epidemiology, Mechanisms and Management, Annals of Translational Medicine, 2(8), pp. 80-95.

13. Fu G, Yuan W, Du W, Yang Z, Fu N, Zheng H, Li Z, Huang Y, Zhang Y, Dai G, Wang H, Li J, Yi J, Yang Q, Tian H, He L, Li G, Zhang J, Fu Z, 2015, Risk Factors Associated with 
Recurrent Strokes in Young and Elderly Patients: A Hospital-based Study, International Journal of Gerontology, 9(2), pp. 63-66

14. Kang K, Park TH, Kim N, Jang MU, Park S, Park J, Ko Y, Lee SJ, Lee KB, Lee J, Kim D, Cho Y, Kim J, Kim D, Cha J, Han M, Lee JS, Lee J, Oh MS, Choi JC, Lee B, Hong K, Bae H, 2016, Recurrent Stroke, Myocardial Infarction, and Major Vascular Events During The First Year After Acute Ischemic Stroke: The Multicenter Prospective Observational Study About Recurrence and Its Determinants After Acute Ischemic Stroke. I, J Stroke Cerebrovasc Dis, 25(3), pp. 656-64.

15. Ismail Setyopranoto, Stroke: Gejala dan Penatalaksanaan. UGM Journal, CDK, 2011, 185/Vol.38 no.4/Mei-Juni.
16. An SJ, Kim TJ, Yoon B, 2017, Epidemiology, Risk Factors, and Clinical Features of Intracerebral Hemorrhage: An Update, Journal of Stroke, 19(1), pp. 3-10.

17. Rist PM, Chalmers J, Arima H, Anderson C, MacMahon S, Woodward M, Kurth T, Tzourio C, 2013, Baseline Cognitive Function, Recurrent Stroke, and Risk of Dementia in Patients With Stroke, Stroke Journal of The American Heart Association, 44, pp. 1790-1795.

18. Cristy I, 2011, Asosiasi Genotip Apoliprotein E dengan Fungsi Kognitif pada Pasien Pasca Stroke Iskemik, Thesis, Semarang: Universitas Diponegoro. 